\title{
EFFECT OF MODERN VERSUS STANDARD OF CARE ANTI-FAILURE MEDICATIONS ON LEFT VENTRICULAR FUNCTION IN HEART FAILURE PATIENTS WITH REDUCED EJECTION FRACTION AS DETECTED BY2D SPECKLE TRACKING ECHOCARDIOGRAPHY
}

\author{
By
Ahmed Mamdouh Abdin, Wael Mohamed Attia and Yasser Abd El-Galel Omar \\ Department of Cardiology, Faculty of Medicine, Al-Azhar University \\ Corresponding author: Ahmed Mamdouh Abdin, \\ E-mail: dr.ahmedmamdouh2628@ gmail.com
}

\begin{abstract}
Background: Heart failure (HF) is a major and growing public health problem, as 21 million adults worldwide are living with heart failure and this number is expected to rise due to aging population, increasing prevalence of risk factors and improved post myocardial infarction (MI) survival.

Objective: This study was discuss the effect of modern versus standard of care anti failure medications on LV function in heart failure patients with reduced ejection fraction using $2 \mathrm{D}$ speckle tracking echocardiography.

Patients and methods: The study population includes 100 heart failure patients with reduced ejection fraction 50 on modern anti-failure medications including angiotensin receptor neprilysin inhibitor (ARNI) and 50 controls on standard anti-failure medications including angiotensin I-converting enzyme inhibitor (ACEI) or angiotensin II receptor blockers (ARBs). All patients attended the outpatient clinic of the Cardiology Department at Al-Azhar University Hospital (Cairo) from March 2020 to March 2021.

Results: There was no significant statistical difference between groups also regard sex distribution there was no significant difference between groups and male were majority in both groups. There was no significant difference between the two studied groups regarding levels of serum creatinine and serum K. Results of comparison of end systolic, end diastolic diameters of left ventricle and diameter of left atrium showed no significant difference between both groups at pre medication assessment but there was a highly significant after medications in both groups $(\mathrm{p}=0.00,0.038$ and 0.035 respectively) also in group A there was a significant decrease from pre to post assessment ( $\mathrm{p}=0.003,0.012$ and 0.004 respectively). There was a statistically significant improve in mitral regurgitation after medication in group A than in group $B(p=0.00)$ but was of no significant in pre medication assessment $(\mathrm{p}=0.48)$.

Conclusion: In HFrEF patients, sacubitril/valsartan significantly improves the mitral regurgitation LV remodeling and with a significant effect on LV diastolic and systolic echo parameters. Accordingly, sacubitril/valsartan could be used at an earlier time in HFrEF patients in order to further limit LV remodeling.
\end{abstract}

Keywords: Left ventricular function, Heart failure, Reduced ejection fraction, 2D speckle tracking, Echocardiography. 


\section{INTRODUCTION}

Heart failure is a leading cause of morbidity and mortality, and causes high health-care-related costs, posing a great burden on both patient and society. It mainly affects older people, and incidence and prevalence rise steeply with age in those aged over 60 years. The most often mentioned prevalence estimate for the adult population at large is $2 \%(1-3 \%)$, and 5-9\% selectively in those aged 65 years and over (van Riet et al., 2016).

The pathophysiologic mechanisms underlying HF development and progression are complex, predominantly involving increased activation of both the renin-angiotensin-aldosterone system (RAAS) and the sympathetic nervous system (SNS). The activation of these systems is counterbalanced by endogenous peptides (eg, natriuretic peptides), which are released in response to myocardial stretch that results from excessive neurohormonal activity (Reed et al., 2014).

Lifestyle interventions aimed at risk reduction comprise an important strategy for preventing $\mathrm{HF}$ and delaying or reversing disease progression following its onset. However, when symptomatic HF develops, pharmacotherapy is typically warranted (Yancy et al., 2017).

Response to pharmacologic therapies for $\mathrm{HF}$ differs depending on cardiac function, which is determined by measurement of ejection fraction (EF). Accordingly, EF has been used to classify patients as having either HF with reduced ejection fraction $(\mathrm{EF} \leq 40 \%$; $\mathrm{HFrEF})$ or $\mathrm{HF}$ with preserved $\mathrm{EF}$ (EF>50\%; $\mathrm{HFpEF})$, although many HF clinical trials have used a lower threshold of $\mathrm{EF} \leq 35 \%$ to define HFrEF (Yancy et al., 2013).

In symptomatic patients with HFrEF, pharmacologic therapies targeting the overactive RAAS and SNS become necessary. Agents targeting these pathways, including angiotensinconverting enzyme inhibitors (ACEIs), angiotensin receptor blockers (ARBs), $\beta$ blockers, and mineralocorticoid receptor antagonists (MRAs), have been the mainstays of HFrEF treatment since the 1990s (McMurray, 2011 and Sokos et al., 2020).

Sacubitril/valsartan (formerly known as LCZ 696) is a first-in-class angiotensin receptor neprilysin inhibitor shown to be superior to enalapril in patients with heart failure with reduced ejection fraction (EF). As such, sacubitril/valsartan has been recommended as a more effective alternative to an angiotensin-converting enzyme (ACE) inhibitor to be used in conjunction with other evidence-based treatments for this type of heart failure (Okumura et al., 2016).

This study was discuss the effect of modern versus standard of care anti failure medications on left ventricular (LV) function in heart failure patients with reduced ejection fraction using $2 \mathrm{D}$ speckle tracking echocardiography.

\section{PATIENTS AND METHODS}

The study population includes 100 heart failure patients with reduced ejection fraction 50 on modern anti-failure medications including ARNI and 50 controls on standard anti-failure medications including ACEI or ARBs. All patients attended the outpatient clinic of the Cardiology Department at Al-Azhar 


\section{EFFECT OF MODERN VERSUS STANDARD OF CARE ANTI-FAILURE... 2771}

University Hospital (Cairo) from March 2020 to March 2021.

Inclusion criteria: Heart failure patients with reduced ejection fraction $\mathrm{LVEF}<$ $40 \%$. >4 weeks stable treatment with ACEI or ARB and beta blocker.

Exclusion criteria: ICD or pacemaker, pregnancy, lactation, moderate or severe renal impairment, hyperkalemia, acute decompensated heart failure and acute coronary syndrome.

\section{All patients underwent:}

1. Informed consent was taken from all Patients for the study participation.

2. Careful history was taken from all patients meeting the inclusion criteria, age, sex, smoking, symptoms.

3. General and local cardiac examination was done for all patient including (vital signs, head \& neck examination, upper \& lower limb examination, abdominal examination \& local examination).

4. Resting surface 12 lead ECG was done for all patients to exclude acute coronary syndrome.

5. Echocardiography was done at the beginning of sacubitril/valsartan treatment and after 6 months.

All patients examined at rest in the left lateral decubitus position to obtain adequate images in different standard views.

LV diastolic and systolic diameters, LVEF were assessed in parasternal long axis view using M-Mode method and from both apical 4-chamber and apical 2chamber views to calculate LVEF using modified Simpson method. 2d speckle tracking echocardiography LV apical 4-chamber, 2-chamber, and 3chamber views were acquired in gray scale and were stored digitally on a hard disk for offline analysis, The LV endocardial border of the end-systolic frame was manually traced. On the basis of this line, the computer automatically created a region of interest including the entire transmural wall for all of the patients, and the software selected natural acoustic markers moving with the tissue. Automatic frame by-frame tracking of these markers during the cardiac cycle (2dimensional [2D] systolic time interval method) yielded a measure of strain, and strain rate at any point of the myocardium. LV GLS and strain rate (GLSR) were measured by averaging the values of all of the segments.

Doppler and tissue Doppler echocardiography to assess LV diastolic dysfunction.

6. Labs urea, creatinine \& $\mathrm{Na}, \mathrm{K} \&$ cardiac enzymes.

\section{Statistical Analysis:}

Data collected throughout history, basic clinical examination, laboratory investigations and outcome measures coded, entered and analyzed using Microsoft Excel software. Data were then imported into Statistical Package for the Social Sciences (SPSS version 20.0) (Statistical Package for the Social Sciences) software for analysis. According to the type of data qualitative represent as number and percentage, quantitative continues group represent by Mean $\pm \mathrm{SD}$, the following tests were used to test differences for significance. Difference and association of qualitative variable by Chi square test (X2) paired by 
sign. Differences between quantitative independent groups by $\mathrm{t}$ test paired by paired $t$, multiple by ANOVA. $P$ value was set at $<0.05$ for significant results \& $<0.001$ for high significant result.

\section{RESULTS}

This table shows that age was distributed as $55.62 \pm 7.65$ and $53.88 \pm 6.11$ respectively between groups A\& B with no significant statistical difference between groups also regard sex distribution there was no significant difference between groups and male were majority in both groups.

As shown in the table there was no significant difference regard distribution of smoking and more than half of both groups were smoker also there was no significant difference regard DM distribution and groups were nearly matched as about two thirds of both groups were diabetics, regard hypertension majority of both studied groups were hypertensive with no significant difference between groups, regard cardiomyopathy there was no significant difference between groups (Table 1).

Table (1): Age, sex and clinical history distribution between studied groups

\begin{tabular}{|c|c|c|c|c|c|}
\hline & & & Group A & Group B & $\mathbf{P}$ \\
\hline \multicolumn{3}{|c|}{ Age } & $55.62 \pm 7.65$ & $53.88 \pm 6.11$ & 0.212 \\
\hline \multirow{4}{*}{ Sex } & \multirow{2}{*}{ Female } & $\mathbf{N}$ & 13 & 11 & \\
\hline & & $\%$ & $26.0 \%$ & $22.0 \%$ & \\
\hline & \multirow{2}{*}{ Male } & $\mathbf{N}$ & 37 & 39 & \multirow{2}{*}{0.64} \\
\hline & & $\%$ & $74.0 \%$ & $78.0 \%$ & \\
\hline \multirow{4}{*}{ Smoking } & \multirow{2}{*}{ No } & $\mathbf{N}$ & 24 & 17 & \multirow{4}{*}{0.155} \\
\hline & & $\%$ & $48.0 \%$ & $34.0 \%$ & \\
\hline & \multirow{2}{*}{ Yes } & $\mathbf{N}$ & 26 & 33 & \\
\hline & & $\%$ & $52.0 \%$ & $66.0 \%$ & \\
\hline \multirow{4}{*}{ DM } & \multirow{2}{*}{ No } & $\mathbf{N}$ & 17 & 16 & \multirow{4}{*}{0.83} \\
\hline & & $\%$ & $34.0 \%$ & $34.0 \%$ & \\
\hline & \multirow{2}{*}{ Yes } & $\mathbf{N}$ & 33 & 34 & \\
\hline & & $\%$ & $66.0 \%$ & $68.0 \%$ & \\
\hline \multirow{4}{*}{ Hypertension } & \multirow{2}{*}{ No } & $\mathbf{N}$ & 6 & 8 & \multirow{4}{*}{0.56} \\
\hline & & $\%$ & $12.0 \%$ & $16.0 \%$ & \\
\hline & \multirow{2}{*}{ Yes } & $\mathbf{N}$ & 44 & 42 & \\
\hline & & $\%$ & $88.0 \%$ & $84.0 \%$ & \\
\hline \multirow{4}{*}{ Cardiomyopathy } & \multirow{2}{*}{ Dilated } & $\mathbf{N}$ & 28 & 21 & \multirow{4}{*}{0.17} \\
\hline & & $\%$ & $56.0 \%$ & $42.0 \%$ & \\
\hline & \multirow{2}{*}{ Ischemic } & $\mathbf{N}$ & 22 & 29 & \\
\hline & & $\%$ & $44.0 \%$ & $58.0 \%$ & \\
\hline
\end{tabular}

There was no significant difference regard laboratory parameters distribution between studied groups (Table 2). 


\section{EFFECT OF MODERN VERSUS STANDARD OF CARE ANTI-FAILURE...}

\section{Table (2): Laboratory parameters distribution between studied groups}

\begin{tabular}{|c|c|c|c|c|c|}
\hline & $\begin{array}{c}\text { Group A before } \\
\text { treatment }\end{array}$ & $\begin{array}{c}\text { Group A after } \\
\text { treatment }\end{array}$ & $\begin{array}{c}\text { Group B before } \\
\text { treatment }\end{array}$ & $\begin{array}{c}\text { Group B after } \\
\text { treatment }\end{array}$ & P \\
\hline S Creatinine & $0.97 \pm 0.17$ & $0.97 \pm 0.18$ & $1.02 \pm 0.18$ & $1.02 \pm 0.22$ & 0.298 \\
\hline Serum K & $3.74 \pm 0.19$ & $3.81 \pm 0.17$ & $3.86 \pm 0.20$ & $3.86 \pm 0.20$ & 0.592 \\
\hline
\end{tabular}

There was no significant difference between studied groups at pre and post however both group were significantly improved with $\mathrm{P}$ value $=0.000 * *$ for Group $\mathrm{A}$ and $\mathrm{P}$ value $=0.00 * *$ for Group $\mathrm{B}$ as regard diastolic dysfunction. Diastolic dysfunction grades were done according E/A ratio as following: Grade 1 (impaired relaxation): $\quad \mathrm{E} / \mathrm{A} \quad<0.8 . \quad$ Grade 2 (pseudonormal filling): E/A 0.8-1.5. 5-3 (restrictive filling): $\mathrm{E} / \mathrm{A}>1.5$.
There was no significant difference between studied groups at pre but at post Group A was significantly associated with mild while group B significantly associated with moderate and sever and only Group A was significantly improved with $\mathrm{P}$ value $=0.000^{* *}$ as regard mitral regurgitation. Mitral regurge severity was assessed by vena contracta width as following: Mild MR: $<3 \mathrm{~cm} 2$. Moderate MR: 3-6 cm2. Severe MR: $>6 \mathrm{~cm} 2$ (Table 3).

Table (3): Diastolic dysfunction and Mitral regurgitation distribution between studied groups at pre and post

\begin{tabular}{|c|c|c|c|c|c|}
\hline & \multicolumn{2}{|c|}{ Group } & \multirow{2}{*}{$\mathbf{P}$} \\
\hline & & & Group A & Group B & \\
\hline \multirow{6}{*}{$\begin{array}{c}\text { Diastolic } \\
\text { Dysfunction Pre }\end{array}$} & \multirow{2}{*}{ Grade 1} & $\mathbf{N}$ & 4 & 5 & \multirow{6}{*}{0.69} \\
\hline & & $\%$ & $8.0 \%$ & $10.0 \%$ & \\
\hline & \multirow{2}{*}{ Grade 2} & $\mathbf{N}$ & 11 & 14 & \\
\hline & & $\%$ & $22.0 \%$ & $28.0 \%$ & \\
\hline & \multirow{2}{*}{ Grade 3} & $\mathbf{N}$ & 35 & 31 & \\
\hline & & $\%$ & $70.0 \%$ & $62.0 \%$ & \\
\hline \multirow{4}{*}{$\begin{array}{c}\text { Diastolic } \\
\text { Dysfunction Post }\end{array}$} & \multirow{2}{*}{ Grade 1} & $\mathbf{N}$ & 10 & 5 & \multirow{4}{*}{0.16} \\
\hline & & $\%$ & $20.0 \%$ & $10.0 \%$ & \\
\hline & \multirow{2}{*}{ Grade 2} & $\mathbf{N}$ & 40 & 45 & \\
\hline & & $\%$ & $80.0 \%$ & $90.0 \%$ & \\
\hline \multirow{6}{*}{ Pre } & \multirow{2}{*}{ Mild } & $\mathbf{N}$ & 5 & 4 & \multirow{6}{*}{0.48} \\
\hline & & $\%$ & $8.0 \%$ & $8.0 \%$ & \\
\hline & \multirow{2}{*}{ Moderate } & $\mathbf{N}$ & 20 & 26 & \\
\hline & & $\%$ & $22.0 \%$ & $52.0 \%$ & \\
\hline & \multirow{2}{*}{ Sever } & $\mathbf{N}$ & 25 & 20 & \\
\hline & & $\%$ & $70.0 \%$ & $40.0 \%$ & \\
\hline \multirow{6}{*}{ Post } & \multirow{2}{*}{ Mild } & $\mathbf{N}$ & 29 & 5 & \multirow{6}{*}{0.00 ** } \\
\hline & & $\%$ & $58.0 \%$ & $10.0 \%$ & \\
\hline & \multirow{2}{*}{ Moderate } & $\mathbf{N}$ & 11 & 30 & \\
\hline & & $\%$ & $22.0 \%$ & $60.0 \%$ & \\
\hline & \multirow{2}{*}{ Sever } & $\mathbf{N}$ & 10 & 15 & \\
\hline & & $\%$ & $20.0 \%$ & $30.0 \%$ & \\
\hline
\end{tabular}

There was no significant difference between groups at pre but at post group A was significantly lower and regard change assessment group A significantly decreased while no significant change founded in group $B$ as regards $\mathrm{EF}$ percentage, end systolic \& diastolic \& LA diameters, and End systolic \& end diastolic volumes (Table 4). 
Table (4): EF percentage, end systolic \& diastolic \& LA diameters, and End systolic $\&$ end diastolic volumes between studied groups at pre and post

\begin{tabular}{|l|c|c|c|}
\hline & Group A & Group B & P \\
\hline EF pre & $29.95 \pm 7.16$ & $30.80 \pm 6.37$ & 0.095 \\
\hline EF Post & $34.54 \pm 7.52$ & $32.30 \pm 7.78$ & $0.028^{*}$ \\
\hline Paired t & 7.65 & 1.685 & \\
\hline P & $0.00^{* *}$ & 0.085 & \\
\hline End systolic diameter Pre & $6.38 \pm 2.05$ & $6.31 \pm 1.94$ & 0.812 \\
\hline End systolic diameter Post & $5.42 \pm 1.54$ & $6.18 \pm 2.11$ & $0.00^{* *}$ \\
\hline Paired t & 3.32 & 1.769 & \\
\hline P & $0.003^{*}$ & 0.085 & \\
\hline End diastolic diameter Pre & $5.15 \pm 1.65$ & $5.21 \pm 1.53$ & 0.389 \\
\hline End diastolic diameter Post & $4.35 \pm 1.08$ & $4.95 \pm 2.11$ & $0.038^{*}$ \\
\hline Paired t & 2.95 & 1.619 & \\
\hline P & $0.012^{*}$ & 0.096 & \\
\hline LA diameter Pre & $5.36 \pm 1.48$ & $5.29 \pm 1.46$ & 0.978 \\
\hline LA diameter Post & $4.41 \pm 1.11$ & $5.02 \pm 1.63$ & $0.035^{*}$ \\
\hline Paired t & 3.29 & 1.419 & \\
\hline P & $0.004^{*}$ & 0.125 & \\
\hline End systolic volume Pre & $145 \pm 33$ & $150 \pm 28$ & 0.812 \\
\hline End systolic volume Post & $105 \pm 28$ & $145 \pm 35$ & $0.00^{* *}$ \\
\hline Paired t & 3.32 & 1.769 & \\
\hline P & $0.003^{*}$ & 0.085 & \\
\hline End diastolic volume Pre & $240 \pm 30$ & $230 \pm 28$ & 0.389 \\
\hline End diastolic volume Post & $190 \pm 35$ & $220 \pm 31$ & $0.038^{*}$ \\
\hline Paired t & 2.95 & 1.619 & \\
\hline P & $0.012^{*}$ & 0.096 & \\
\hline
\end{tabular}

\section{DISCUSSION}

The present study wes a case control included 100 patients with reduced ejection fraction heart failure (LVEF< $40 \%$ ) divided into two groups: group A included 50 patients on modern antifailure medications including ARNI and group B included 50 patients on standard anti-failure medications including ACEI or ARBs as controls. The aim of this study was to evaluate the effect of modern versus standard of care anti-failure medications on LV function in heart failure patients with reduced ejection fraction using 2D speckle tracking echocardiography done at the beginning of treatment and after 6 months.

The mean age of patients in the current study was $55.62 \pm 7.65$ and $53.88 \pm 6.11$ years in group A \& B respectively, they were 24 female and 66 male with male predominance in both groups but with no statistical significance between both groups regarding age, sex also there was no significant difference between both groups regarding history of smoking, DM, HTN and cardiomyopathy.

In the current study, results of laboratory investigations showed that there was no significant difference between the two studied groups regarding levels of serum Creatinine and serum $\mathrm{K}$. Results of McMurray et al. (2014) double blinded trial on 8442 patients with class II, III, or IV heart failure and an ejection fraction of $40 \%$ or less to receive either LCZ696 (at a dose of $200 \mathrm{mg}$ twice daily) or enalapril (at a dose of $10 \mathrm{mg}$ twice daily) and results showed that a serum 
potassium level of more than $6.0 \mathrm{mmol}$ per liter were reported less frequently in the LCZ696 group than in the enalapril group $(11.3 \%$ vs $14.3 \%$ ) also higher levels of serum creatinine $>2.5 \mathrm{mg} / \mathrm{dl}$ were reported more in the enalapril group than the LCZ696 group (4.5\% vs 3.3\% ) as the LCZ696 group had lower proportions with renal impairment and hyperkalemia than the enalapril group. This was in contrast to study of Hsiao et al. (2019) who showed that renal function did not change significantly after 1 year of ARNI treatment as the creatinine level showed a slight non-significant increase (mean: but level of serum $\mathrm{K}$ had a significant higher values at 12 months follow up than of baseline level .

Cardiac reverse remodeling (CRR) generally refers to improvements in damaged ventricular/atrial volume, dimension, and shape. Improvements in CRR have been used to evaluate the effects of ARNI in several randomized controlled trials (RCTs) and observational studies (Barrett et al., 2018, Kang et al., 2019 and Groba-Marco et al., 2019). The results of some of these studies support the superior effects of ARNI over ACEIs/ARBs on remodeling (Almufleh et al., 2017 and De Diego et al., 2018).

However, the PRIME (Pharmacological Reduction of Functional, Ischemic Mitral Regurgitation) prospective randomized study by Kang et al. (2019) has demonstrated that an angiotensin receptor neprilysin inhibitor is more effective in improving functional mitral regurgitation associated with heart failure than an angiotensin receptor blocker. The authors found that in comparison with valsartan, sacubitril/valsartan further reduces the effective regurgitant orifice area, left ventricular end-diastolic volume index, left atrial volume index, and the ratio of mitral in- flow velocity to mitral annular relaxation velocity $\left(E / E^{\prime}\right)$. No benefit was observed in LVEF but the authors excluded the more severe patients with LVEF $\leq 25 \%$ and only patients with significant mitral regurgitation. This inconsistency may affect the judgment of ARNI effects. Furthermore, the results in terms of different doses and follow-up periods remain inconclusive. Most studies have demonstrated a dose-dependent effect of ARNI on CRR indices, with higher doses resulting in greater CRR (Solomon et al., 2012 and Schmieder et al., 2017).

However, other studies have produced different conclusions (De Diego et al., 2018 and Martens et al., 2018). Martens et al. (2018) found that LVEF was enhanced after longer treatment with ARNI. This coincided with no significant short-term impacts on CRR in RCT by Solomon et al. (2012), compared with other studies that demonstrated short-term effectiveness. These aspects therefore remain controversial (De Diego et al., 2018 and Hlavata et al., 2018). In the present study, our results showed that there was no significant difference between both groups regarding diastolic dysfunction pre and post medications. While, results of comparison of ejection fraction $(\mathrm{EF})$ at pre medication assessment showed no significant difference between study groups but after medication there was a highly significant difference between both groups being higher in group A also in group A there was a significant increase in post medication 
assessment than pre medication (from $29.95 \pm 7.16$ to $34.54 \pm 7.52, \mathrm{p}=0.00$ ) but no significant difference was found in group B .

This comes in harmony with results of Bayard et al. (2019) prospective study on 41 patients using PARADIGM-HF criteria: Class II, III, or IV HF; ejection fraction (EF) of $40 \%$ or less; hospitalized for $\mathrm{HF}$ within the previous 12 months, TTE Echo evaluation was performed before initiating sacubitril/valsartan and 3 months after optimal dose adjustment.(Based on previous studies, patients with (absolute) improvement in left ventricular ejection fraction $(\mathrm{LVEF}) \geq$ $5 \%$ were considered significant sacubitril/valsartan responders. Pitzalis et al. (2010) results of comparison between before and after treatment with sacubitril/valsartan showed a significant improve in ejection fraction.

Similarly, Chang et al. (2020) study on 437chronic HF patients with left ventricular ejection fraction (LVEF) less than $40 \%$ who received sacubitril/valsartan and results showed that approximately one third of patients would have LVEF improved at least $10 \%$ points from baseline, and a total of $17.6 \%$ patients achieved complete restoration of their LVEF to $50 \%$ or greater after sacubitril / valsartan treatment within one year .

In the current study, results of comparison of end systolic, end diastolic diameters of left ventricle and diameter of left atrium showed no significant difference between both groups at pre medication assessment but there was a highly significant after medications in both groups Also in group A, there was a significant decrease from pre to post assessment .

This was in agreement with results of Chang et al. (2020) study showed that after 1 year therapy with sacubitril/valsartan a significant decrease in left atrial diameter. end diastolic diameter . end systolic diameter . Results of Bayard et al. (2019) showed a significant decrease in left ventricular end diastolic diameter after treatment with sacubitril/valsartan than before; although the end systolic diameter decreased from $49 \pm 7 \mathrm{~mm}$ to $48 \pm 5 \mathrm{~mm}$ but was of no significance .

In contrast, Mazzetti et al. (2020) results showed that there were nonsignificant differences in the size of the left atrium, right ventricular function, and pulmonary pressures were found at 6 months.

An increased left ventricle end diastolic diameter suggested a long and severe remodeling process of the LV, which is difficult to be reversed (Chang et al., 2020). Similar concepts were presented in published manuscripts of percutaneous mitral-valve repair for HFrEF patients with secondary mitral regurgitation. In Obadia et al. (2018) trial, percutaneous mitral-valve repair therapy failed to show any survival benefit over medical therapy during the one year follow-up.

However, in Stone et al. (2018) trial, patients receiving the percutaneous mitralvalve repair had $47 \%$ lower risk of $\mathrm{HF}$ hospitalization and $38 \%$ lower risk of allcause mortality than patients receiving medical therapy alone within 2 years of follow-up. These differences might be partially explained by different degrees of 


\section{EFFECT OF MODERN VERSUS STANDARD OF CARE ANTI-FAILURE...}

HF disease progression, as the indexed left-ventricular end-diastolic volume was higher in Obadia et al. (2018) trial (135 \pm $37 \mathrm{ml} / \mathrm{m} 2$ ) and lower in Stone et al. (2018) trial $(101 \pm 34 \mathrm{ml} / \mathrm{m} 2)$.

The current study results showed a statistically significant improve in mitral regurgitation after medication in group $A$ than in group $B(p=0.00)$ but was of no significant in pre medication assessment $(\mathrm{p}=0.48)$. Another study results of Chang et al. (2020) revealed that the severities of mitral regurgitation and tricuspid regurgitation also decreased significantly after 1year of follow-up of sacubitril/ valsartan treatment ( $p<0.001$ for both).

This was in accordance with Bayard et al. (2019) who reported that sacubitril/valsartan responders had less significant mitral regurgitation compared to non-responders $\quad(\mathrm{p}=0.01)$, Sacubitril/valsartan responders displayed less severe LV remodelling and less significant mitral regurgitation, Accordingly, sacubitril/valsartan could be used at an earlier time in HFrEF patients in order to further limit LV remodeling. More Prior studies on sacubitril/valsartan remodeling properties showed an improvement of LV volumes and mass (Almufleh et al., 2017 and Liu et al., 2020).

\section{CONCLUSION}

In HFrEF patients, sacubitril/valsartan significantly improves volumes and diameters by $2 \mathrm{D}$ echo, mitral regurgitation and diastolic dysfunction, and also improves ejection fraction, furthermore it improves average global longitudinal strain as well as symptoms of heart failure.
So, in the context of this study, it is recommended early treatment by sacubitril/valsartan in patients with heart failure with reduced ejection fraction.

\section{REFERENCES}

1. Almufleh A, Marbach J, Chih S, Stadnick E, Davies R, Liu $P$ and Mielniczuk $L$. (2017): Ejection fraction improvement and reverse remodeling achieved with Sacubitril/Valsartan in heart failure with reduced ejection fraction patients. American Journal of Cardiovascular Disease, 7(6): 108112.

2. Barrett MJ, Hammond M, Zhou S, Hanlon RO, Campbell P and Mcdonald K. (2018): Effect of sacubitril/valsartan therapy on risk stratification biomarkers in a real-world heart failure population. Eur J Heart Fail., 19:585586.

3. Bayard G, Da Costa A, Pierrard R, Roméyer-Bouchard C, Guichard JB and Isaaz K. (2019): Impact of sacubitril/valsartan on echo parameters in heart failure patients with reduced ejection fraction a prospective evaluation. IJC Heart and Vasculature, 25: 100418-23.

4. Chang HY, Chen KC, Fong MC, Feng AN, Fu HN, Huang KC and Yin WH. (2020): Recovery of left ventricular dysfunction after sacubitril/valsartan: predictors and management. Journal of Cardiology, 75(3): 233-241.

5. De Diego C, González-Torres L, Núñez JM, Centurión ER, De Lara $G$ and Macias $M$. (2018): Angiotensin-neprilysin inhibition further reverses cardiac remodeling as compared to angiotensin inhibition in reduced heart failure patients. Europace, 20: 39-45.

6. Groba Marco M, Singh $M$ and Galvan Ruiz M. (2018): Early left ventricular reverse remodeling after sacubitril/valsartan treatment in clinical practice. Eur J Heart Fail., 20: 22532.

7. Hlavata K, Hoskova L, Franekova J, Jabor A, Kautzner J, Melenovsky V and Benes J. (2018): Transition from angiotensin converting enzyme inhibitor/angiotensin II 
receptor blocker to sacubitril/valsartan in chronic heart failure patients: initial experiences in clinical practice. Cor Vasa., 60: 209-214.

8. Hsiao FC, Wang CL, Chang PC, Lu YY, Huang CY and Chu PH. (2020): Angiotensin receptor neprilysin inhibitor for patients with heart failure and reduced ejection fraction: real-world experience from Taiwan. Journal of Cardiovascular Pharmacology and Therapeutics, 25(2): 152157.

9. Kang DH, Park SJ, Shin SH, Hong GR, Lee S, Kim MS, Yun SC, Song JM, Park SW and Kim JJ. (2019): Angiotensin receptor neprilysin inhibitor for functional mitral regurgitation. Circulation, 139:1354-1365.

10. Liu LW, Wu PC, Chiu MY, Tu PF and Fang CC. (2020): Sacubitril/Valsartan Improves Left Ventricular Ejection Fraction and Reverses Cardiac Remodeling in Taiwanese Patients with Heart Failure and Reduced Ejection Fraction. Acta Cardiologica Sinica., 36(2): 125-132.

11. Martens P, Beliën $H$, Dupont $M$, Vandervoort $P$ and Mullens W. (2018): The reverse remodeling response to sacubitril/valsartan therapy in heart failure with reduced ejection fraction. Cardiovasc Ther., 36: 12435-42.

12. McMurray JJ, Packer M, Desai AS, Gong J, Lefkowitz MP, Rizkala AR, Rouleau J, Shi VC, Solomon SD, Swedberg $K$ and Zile MR. (2014): PARADIGM-HF Committees and Investigators. Dual angiotensin receptor and neprilysin inhibition as an alternative to angiotensin-converting enzyme inhibition in patients with chronic systolic heart failure: rationale for and design of the Prospective comparison of ARNI with ACEI to Determine Impact on Global Mortality and morbidity in Heart Failure trial (PARADIGM-HF). Eur J Heart Fail., 15:1062-1073.

13. McMurray JJ. (2011): Consensus to Emphasis: the overwhelming evidence which makes blockade of the renin-angiotensinaldosterone system the cornerstone of therapy for systolic heart failure. Eur J Heart Fail., 13(9): 929-936.
14. Obadia JF, Messika-Zeitoun D, Leurent G, Iung B, Bonnet $G$ and Piriou N, (2018): Percutaneous repair or medical treatment for secondary mitral regurgitation. N Engl J Med., 379: 2297-306.

15. Okumura N, Jhund PS, Gong J, Lefkowitz MP, Rizkala AR, Rouleau JL, Shi VC, Swedberg K, Zile MR, Solomon SD and Packer M. (2016): Effects of sacubitril/valsartan in the paradigm-HF trial (Prospective Comparison of ARNI with ACEI to Determine Impact on Global Mortality and Morbidity in Heart Failure) according to background therapy. Circulation: Heart Failure, 9(9): 3212-18.

16. Pitzalis MV, Iacoviello $M$, Romito $R$, Guida P, De Tommasi E, Luzzi G, Anaclerio M, Forleo C and Rizzon P. (2010): Ventricular asynchrony predicts a better outcome in patients with chronic heart failure receiving cardiac resynchronization therapy. Journal of the American College of Cardiology, 45(1): 65-69.

17. Reed BN, Street SE and Jensen BC. (2014): Time and technology will tell: the pathophysiologic basis of neurohormonal modulation in heart failure. Heart Fail Clin., 10(4):543-557.

18. Schmieder RE, Wagner F, Mayr M, Delles C, Ott C, Keicher C, Hrabak Paar M, Heye T, Aichner S, Khder Y, Yates D, Albrecht D, Langenickel T, Freyhardt P, Janka R and Bremerich J. (2017): The effect of sacubitril/valsartan compared to olmesartan on cardiovascular remodeling in subjects with essential hypertension: the results of a randomized, double blind, active controlled study. Eur Heart J., 38:3308-3317.

19. Sokos GG and Raina A. (2020): Understanding the early mortality benefit observed in the PARADIGM-HF trial: considerations for the management of heart failure with sacubitril/ valsartan. Vascular Health and Risk Management, 16: 41-51.

20. Solomon SD, Zile M, Pieske B, Voors A, Shah A, Kraigher Krainer E, Shi V, Bransford T, Takeuchi M, Gong J, Lefkowitz M, Packer M and McMurray JJ. (2012): The angiotensin receptor neprilysin 
inhibitor LCZ696 in heart failure with preserved ejection fraction: a phase 2 double blind randomized controlled trial. Lancet, 380:1387-1395.

21. Stone GW, Lindenfeld J, Abraham WT, Kar S, Lim DS and Mishell JM. (2018): Transcatheter mitral-valve repair in patients with heart failure. N Engl J Med., 379:230718.

22. van Riet EE, Hoes AW, Wagenaar KP, Limburg A, Landman MA and Rutten FH. (2016): Epidemiology of heart failure: the prevalence of heart failure and ventricular dysfunction in older adults over time. A systematic review. European Journal of Heart Failure, 18(3): 242-252.

23. Yancy CW, Jessup M, Bozkurt B, Butler J, Casey DE Jr, Drazner MH, Fonarow GC, Geraci SA, Horwich T, Januzzi JL, Johnson MR, Kasper EK, Levy WC, Masoudi FA, McBride PE, McMurray JJ, Mitchell JE, Peterson PN, Riegel B and
Sam F. (2013): American College of Cardiology Foundation/American Heart Association Task Force on Practice Guidelines. 2013 ACCF/AHA guideline for the management of heart failure: a report of the American College of Cardiology Foundation/American Heart Association Task Force on practice guidelines. Circulation, 128(16): 240-327.

24. Yancy CW, Jessup M, Bozkurt B, Butler J, Casey DE Jr, Colvin MM, Drazner MH, Filippatos GS, Fonarow GC, Givertz MM, Hollenberg SM, Lindenfeld J, Masoudi FA, McBride PE, Peterson PN, Stevenson LW and Westlake C. (2017): 2017 ACC/AHA/HFSA focused update of the 2013 ACCF/AHA guideline for the management of heart failure: a report of the American college of cardiology/American heart association task force on clinical practice guidelines and the heart failure society of America. Circulation, 136(6):137-161. 
تأثثير العلاج الحديث مقارنة مع العلاج التقليدي على وظيفة

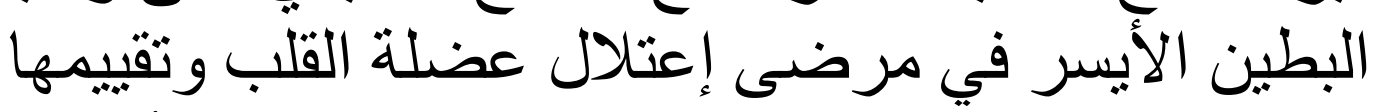
بواسطة تخطيط صدى القلب لتتبع البقع ثنائي الأبعاد

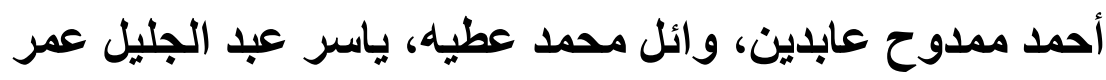
قسم أمراض القلب و الأوعية الدموية، كلية الطب، جامعة الازهر

E-mail: dr.ahmedmamdouh2628@gmail.com

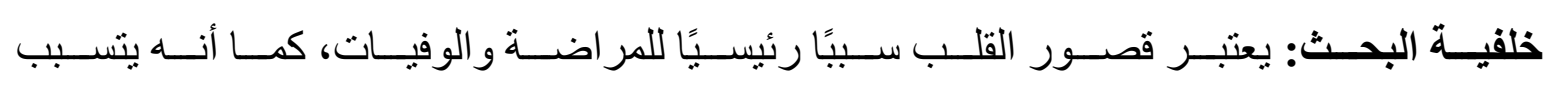

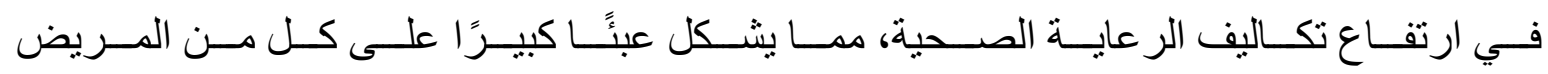

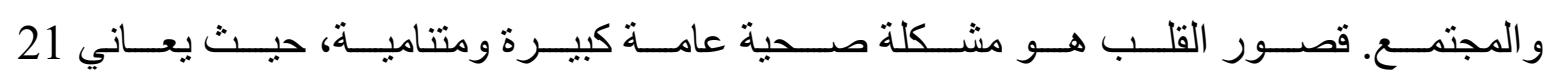

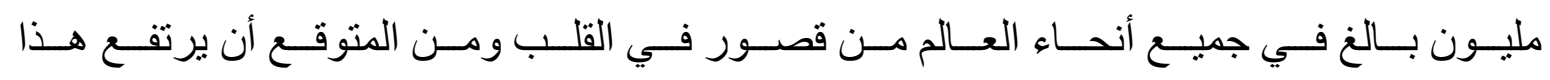
العدد بسبب الثيخوخة، وزيادة إنتشار عو امل الخطر.

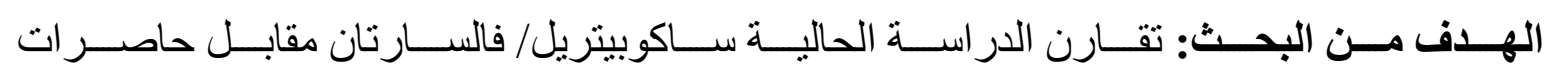

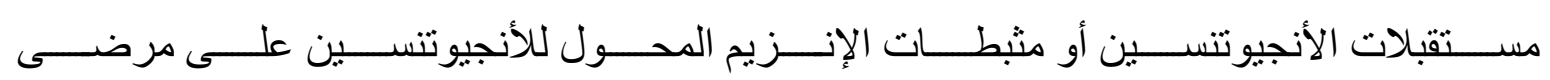
ضعف عضلة القلب باستخدام تخطيط صدى القلب بتتبع البقعة ثنائية الأبعاد.

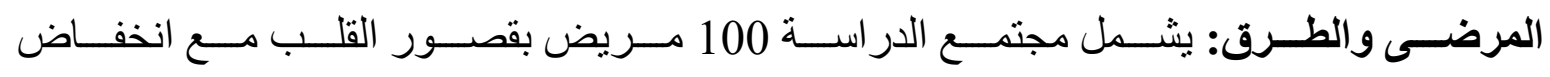

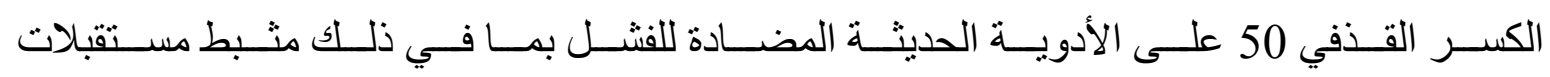

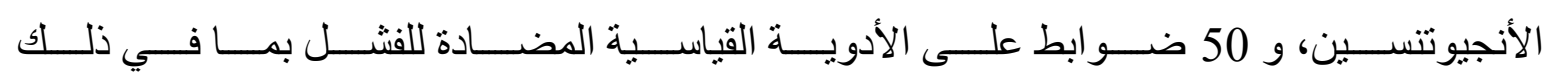

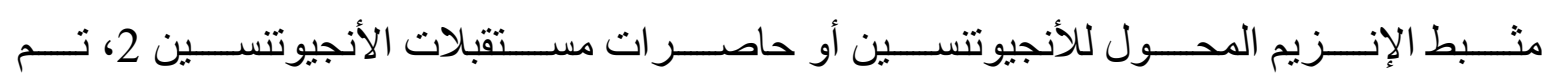
جمع المرضى و العمل في مستشفيات جامعة الأز هر.

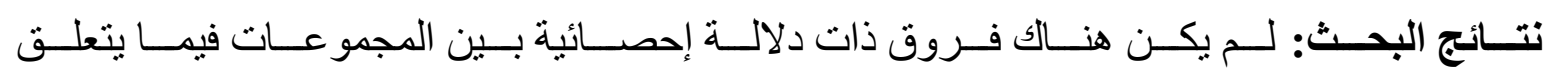

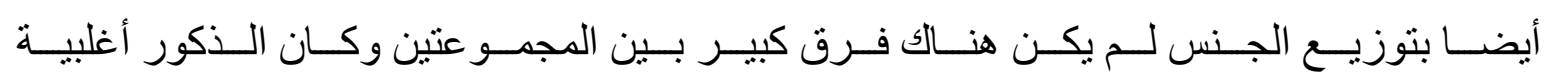

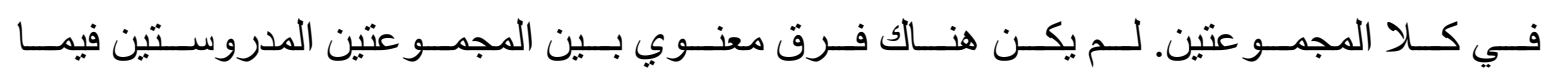

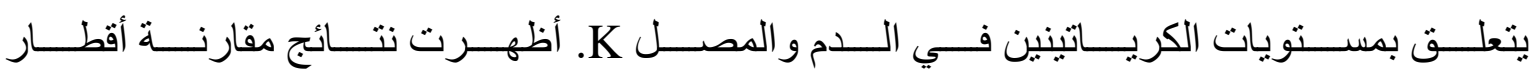

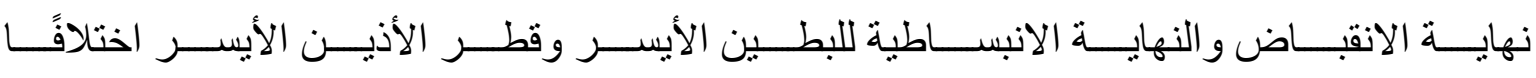

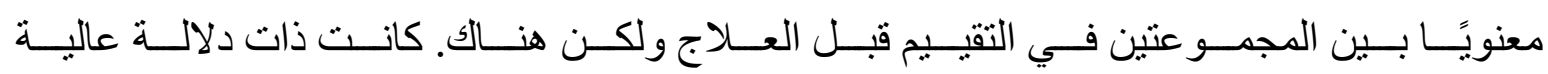

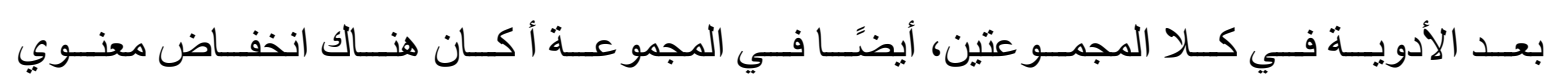


EFFECT OF MODERN VERSUS STANDARD OF CARE ANTI-FAILURE... ${ }^{2781}$

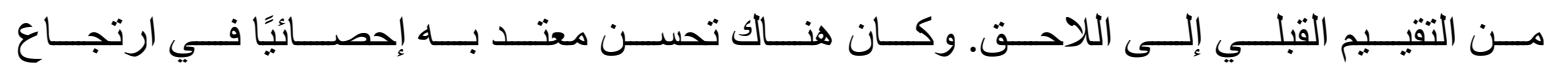

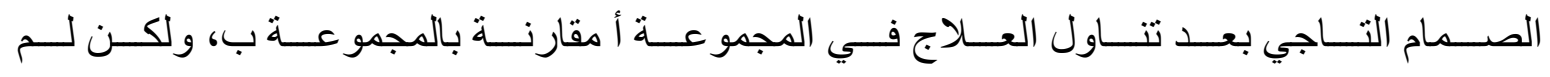
يكن ذا دلالة إحصائية في تقييم ما قبل العلاج.

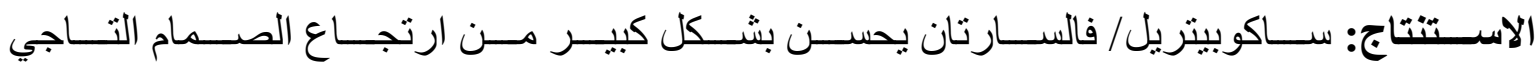

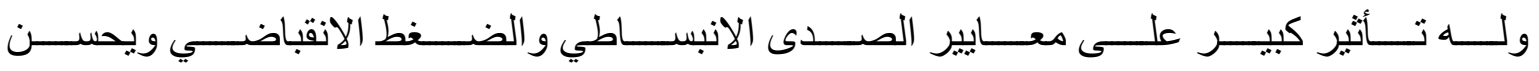

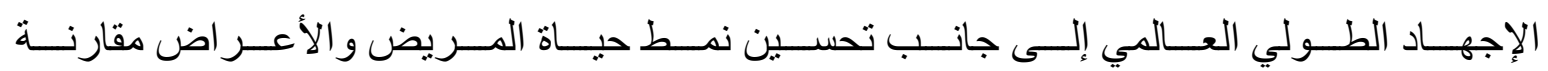

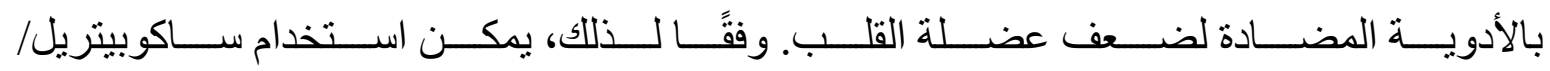

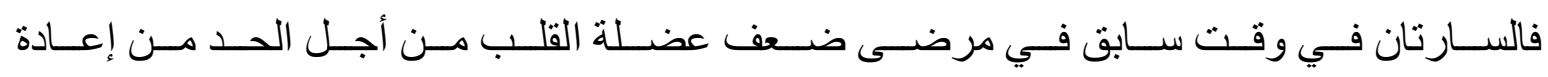
تشكيل الجهد المنخفض.

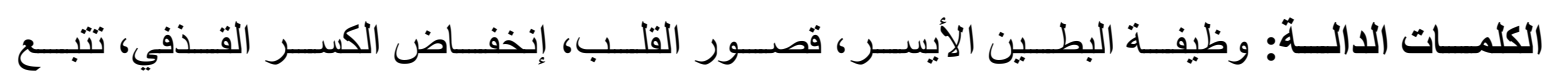
البقعة ثنائية الأبعاد، تخطيط صدى القلب. 